\title{
A Robust Portable Natural Language Data Base Interface
}

\author{
Jerrold M. Ginsparg \\ Bell Laboratories \\ Murray Hill, New Jersey 07974
}

\section{ABSTRACT}

This paper describes a NL data base interface which consists of two parts: a Natural Language Processor (NLP) and a data base application program (DBAP). The NLP is a general purpose language processor which builds a formal representation of the meaning of the English utterances it is given. The DBAP is an algorithm with builds a query in a aug. mented relational algebra from the output of the NLP. This approach yields an interface which is both extremely robust and portable.

\section{Introduction}

This paper describes an extremely robust and portable NL data base interface which consists of two parts: a Natural Language Processor (NLP) and a data base application program (DBAP). The NLP is a general purpose language processor which builds a formal representation of the meaning of the English utterances it is given. The DBAP is an algorithm with builds a query in an jugmented relational algebra from the output of the NLP.

The system is portable. or data base independent, because all that is needed to set up a new data base interface are definitions for concepts the NLP doesn't have. plus what 1 will call the "data base connection". i.e.. the connection between the relations in the data base and the NLP's concepts. Demonstrating the portability and the robustness gained from using a general purpose NLP are the main subjects of this paper Discussion of the NLP will be limited to its interaction with the DBAP and the data base connection, which by design. is minimal. [Ginsparg $S$ | contains a description of the NLP parsing algorithm.

\section{NLP overview}

The formal language the NLP uses to represent meaning is a variunt of semantic nets [Quillian 81. For example, the utterances

"The color of the house is green."

"The house's coior is green."

"Green is the color that the house is."

would all be iransiormed to:

sl Isa: *olored

Tense: present

Colored: $\mathrm{g} 2$

Color: $\mathrm{g} 3$

g2 Isa: "house

Definite: the

23 Isa: "iolor

Value: green where "colored". "color" and ""house" are system primitives called concepts. Each concept is an extended case frame. [Fillmore 2]. The meaning of each concept to the system is implicit in its relation to the other system concepts and the way the system manipulates it.

Each concept has case preferences associated with its iases. For example. the case preference of color is "color and the case preference of colored is "physical-object.

The case preferences induce a network among the concepts. For example. "color is connected to "physical-object via the path: ["physical-object colored "colored color "colorl. In uddition. "color is connected to "writing-implement. a refinement of "physicalobject, by a path whose meaning is that the writing implement writes with that color. This network is used by the NLP to deter. mine the meaning of many modifications. For example. "red pencil" is either a pencil which is red or a pencil that writes red. depending on which path is chosen. In the absence of contextual information. the NLP chooses the shortest path.

In normal usage. case preferences are often broken. The meaning of the broken preference involves coercing the offending concept to another one via a path in the network. Examples are:

"Turn on the soup."

"Turn on the burner that has soup on it."

"My car will drink beer."

"The passengers in my car will drink beer."

\section{The Data Base Connection}

Consider the data base given by the following scheme:

Suppliers(sno.sname.scity)

Projects(jno.jname.jcity)

Parts(pno.pname.color.cost,weight)

Spj(sno.pno.jno.quantity, m.y)

Suppliers and proiects have a number, nume and sity Parts hasc a number, name. color. cost and wejght. Supplier imo sumlles quamme of parts pmo to project mo in month enof vear .

The data base connection has four parts:

1. Connecting each relation to the appropriate concept:

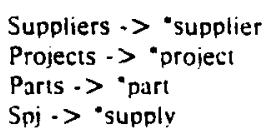


2. Connecting each attribute to the appropriate concept:

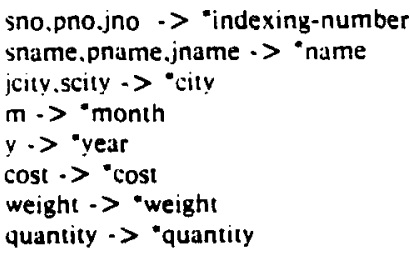

3. Capturing the information implicit in each relation:

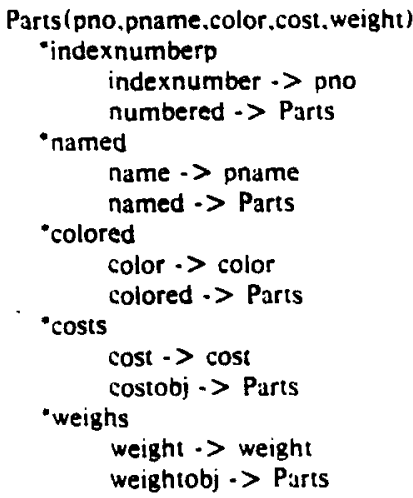

The amoum case of "spend maps to a computation rather than a ingle attribute. If all the atuributes in the computation are not present in the relation being detined. the query building program oons in the necessary extra relations. So the definition of "spend works equally well in the crample scheme as well as in a scheme (eg.. Spj(sno.pno.jno.cost.quantity)) in which tine cost of a part depended on the supplier.

\section{Creating pseudo relations}

\section{Pseudo Cities jcity,scity}

This creates a pseudo relation. Cities(cname). so that the query building algorithm an treat all attributes as if they belong to $\mathrm{J}$ relation. The query produced by the system will refer to the Cities relation. A postprocessor is used to remove references to pseudo relations from the final query. Pseudo relations are important because they ensure uniform handling of attributes. With the pseudo Cities relation, questions like "Who supplies every city?" and "List the cities." can be treated identically to "Who supplies every project?" and "List the suppliers."

The remainder of the data base connection is a sel of switches which provide information on how to print out the relations. whether all proper nouns have been defined or are to be inferred. whether relations are multivalued, etc. The switch settings and the four components above constitute the entire data base connection. Nothing else is needed.

The network of concepts in the NLP should only be augmented for a particular data base: never changed. Yet different data base schemes will require different representations for the same word. For example. depending on the data base scheme. it cuuld be correct to represent "box" as either.

\section{gl Isa: "part}

Conditions: "named(gl,box)

32 Isa: "container

Conditions: "named(g2.box)

g3 Isa: "box

The solution is to detine each word to map to the lowest possible concept. When a concept is encountered that has a data base relj. tion associated with It. there is no problem. If there is no relation associated with a concept. the NLP searchs for a concept that does correspond to a relation and is also a generalization of the concept in question. If one is lound. it is used with an appropriate condition. usually "titled or "named. So "box" has a detinition which maps to "box. In the data base connection given above. "box" would be instantiated as a "part" since "box" is a refinement of "part" and no relation maps to "box."

\section{Using the Connection}

The information in the data base connection is primarily used ill building the query (section 5.1. But il is ilso used (1) .upement the knowledge buse of the NLP

The data base connection is used to overwrite the VLP'; idse preferences. Since located $\rightarrow>$ Sunpliers or Prolects. the preterence 1) located is specitied 10 suppliers or protects. This enubles the VLP to interpret the first noun groun in "Do) ans iuppliers thall sunply wideets localed in london also supplv screws " as "suppliers in London that supply widgets" rather than "suppliers that juppls London widyasts". This is in contrast to Kawron 31 which uses I separate "disambigualor" phase to efimmate parses that do not make sense in the concentual scheme of the dalla base

The additional prefierence information supplied by the datit base connection is used to induce coercions fiection 2.) thall would not be made in the absence of the connection or under inother datld 
base scheme. "Who supplies London" does not break any real world prefierences. but does break one of the preferences induced by this data base scheme, namely that Suppliee is a project. London, a "city, is coerced to "project via the path ["project located "located location "cityl and the question is understood to mean "Who supplies projects which are in London."

As mentioned in Section 2.. the NLP determines the meanings of many modifications by searching for connections in a semantic net. The data base connection is used to augment and highlight the existing network of the NLP. If the user says, "What colors do parts come in?", the NLP can infer that the meaning of "come-in" intended by the user is "colored since the only path through the net between "color and "part derived from the case preferences induced by the data base connection is

["part colored"colored color "color]

Similarly, when given the noun group "London suppliers" the meaning is determined by tracing the shortest path through the highlighted net.

["supplier locared"located locanion" city]

The longer path connecting "supplier and "city,

["supplier supplier "supply suppliee "project locared "location locarion "cityl

which means "the suppliers that supply to london projects" is found when the NLP rejects the first meaning because of context. if the user says "What are the locations of the London suppliers" the system assumes the second meaning since the first (in the domain of this data base scheme) leads 10 a tautological reading. The NLP is able to infer that "The locations of the suppliers located in London" is tautological while "The locations of the suppliers located in England" is not, because the data base connection has specified "located to be a single valued concept with its locamon case typed to "city. If the system were isked for the locations of suppliers in England. and it knew England was a country, the question would be incerpreted as "the cities of the suppiliers that are located in cities located in England."

\section{A trace of the query building algorithm.}

The query butlding algorithm is illustrated by tracing its operation on the question. "Does blake supply any projects in london?"

The NLP's meaning representation for this question is shown below

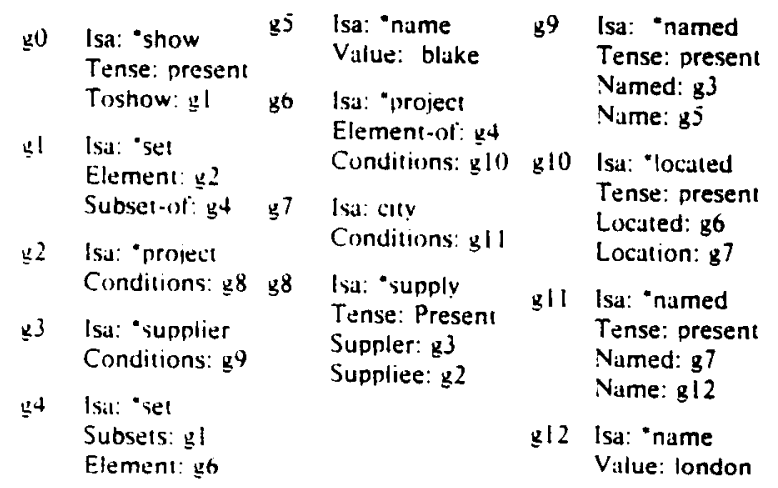

The NLP treats most true-false questions with indetinites as requests for the data which would make the statement true. The question's meaning is "to show the subset of london proiects that are supplied by Blake."

The query building algorithm builds up the query recursively Given an instantiated concept with cases. It expands the contents of each case and links the results together with the relation corresponding to the concept. Given an instantiated concept with conditions, it expands each condition. For the example. we have.

\section{1> Expand 81}

2> Expand 82, the Element of $\mathrm{g}$

3) Expand $\mathrm{g} 8$, the Condition of $\mathrm{g} 2$.

4> Expand $\mathrm{g} 3$, the Supplier case of $\mathrm{g} 8$.

5 Expand 89. the Condition of 83 . From the data base connection, a "named whose named case is a "supplier is realized by the Suppliers relation using the sname attribute. So we have.

$4<89$ - select from Suppliers w/iere sname - blake

$3<$ From the data base connection. a "supplv is realized by the Spj relation. This results in, $\mathrm{g} 8 \mathrm{a}$ - project jno from join $\mathrm{Spj}$ to $\mathrm{g} 9$

$2<\mathrm{g} 8$ - join g8a 10 Projects 88 is the projects supplied by Blake.

2> Expand 84 , the set $g l$ is a subset of. by expanding its etement. 86

3) Expand 810 , the Condition of 86

4 Expand $\mathrm{g} 7$. the location case of g 10 yielding gll - select from Cities w/iere cname - Iondon

$3<$ A located with a project in the locared case is realized by the Projects relation using the jcity attribute. So we have. gl0a $=$ join Projects $10 \mathrm{gll}$ where jcity = iname $\mathrm{glOb}=$ project jno from $\mathrm{gl0 \textrm {a }}$

$2<\mathrm{g} 10=$ join $\mathrm{g} 10 \mathrm{~b}$ to Projects $\mathrm{g} 10$ is the projects in London.

$1<$ Intersect the expansions of 32 and 84 and project the protect names.

g13 - project jname troin imersechong g g10

The entire query is.

b9 = select from Suppiiers where sname = blake

$\mathbf{8 a}=$ proiecr jno trom join Spj $10 \mathrm{~g} 9$

$\mathbf{y} 8=$ join 88 a 10 Projects

g10 select from Projects where icitv = Iondon

g13 = proiect iname trom imersechous $\mathrm{g} 8 \mathrm{\omega} 10$

where the extrd poin resulting from the pseudo Cilles relatlom hat been removed by the post processor (section i.)

Entirely as a side effect of the wat the query is generated, the it tem can easily correct any false assumplons made by the user \{Kaplan 7\}. For example. if there were no proiects in London. gli would be empty and system would respond. generating from the instantiated concept gi0 li.e.. the names used in query sorresnond to the names used in the knowledge representation!. "There ar no suppliers locuted in London." $V_{n}$.ddditional "bolited presupposition" mechanism is required. 
The remainder of this section discusses several aspects of the query building process that the trace does not show.

Negations are handled by introducing a set difference when neces. sary. If the example query were "Does Blake supply any projects that aren't in London?". the expansion of $\mathrm{g} 7$ would have been.

Expand $\mathrm{g} 7$, the location case of gl0 yielding

glla = select from Cities where cname = london

$\mathrm{g} 1 \mathrm{l}$ - difference of Cities and $\mathrm{glla}$

Conjunctions are handled by introducing an an intersection or union. If the example query were "Does Blake supply any projects in London or Paris'm, the locarion case of gl0 would have been the conjunction $\mathrm{g} 13$.

z13 isa "conjunction

Type: or

Conjoins: $\mathrm{g} 7 \mathrm{~g} 14$

glt Isa: "city Conditions: 815

g15 Isa: "named

Named: 815

Name: g16

816 Isa: "name

Value: paris

The result of expanding $\mathrm{g} \mid 3$ would be.

gll - select trom Cities where cname $=$ london

$\underline{15}=$ select trom Cities where cname $=$ paris

$\mathrm{g} 13=$ Unon of $\mathrm{g} 11$ and $\mathrm{g} 15$

In general, "or" becomes a union and "and" becomes an intersection. However, if an "and" conjunction is in a single valued case (information obtained from the data base connection), a union is used instead. Thus "Who supplies london and paris'" is interpreced as "Who supplies both London and Paris?" and "Who is in London and Paris?" is interpreted as "Who is in London and who is in Paris?" in the example data base scheme.

Quantifiers are handled by a post processing phase. "Does blake supply every project in London'?" is handled identically to "Does Blake supply a prolect in London?" except that the expansion of "projects in London" is marked so that the post processor will be ialled. The post processor adds on a set of commands which check that the set difference of London proiects and London protects that Blake supplies is empty. The resulting query is.



The tirst four commands are the query for "Does Blake supply a provect in London'”. The last four check that no project in LonJon is nol supplied by Blake.

1 minor modification is needed to cover cases in which the query building algorithm is expanding an instantiated concept that references an instiantiated concept that is being expanded in a higher recursive call. The following examples illustrate this. Consider the dala base scheme below, taken from IUlliman 9l.
Frequents(drinker.bar)

Serves(bar, beer)

Likes(drinker, beer)

If we ask. "Who frequents a bar that serves a beer John likes?". we get the following query.



If we ask "Who frequents a bar that serves a beer that he likes?" the correct query is.

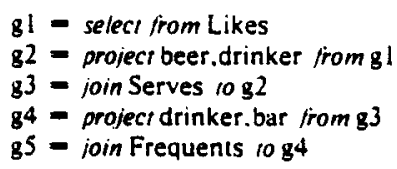

In the first query "beer" was the only attribute projected irom gl In the second. the system projected both "beer" and "drinker" because in expanding "a beer he likes" it needed to expand an instantiated concept (the one representing "who") that was already being expanded.

All of these cases interact gracefully with one unother. For example. there is no problem in handling "Who supplies every project that is not supplied by blake and bowles"

\section{Advantages of this approach}

The system can understand anything it has a concept about. regardless of whether the concept is attuched to a retation in the data base scheme. In the Suppliers data base from Section 4. parts had costs and weights associated with them, but not sizes. If a user asks "How big are each of the parts?" and the interiace has a "size primitive (which it does), the query building process will attempt to find the relation which "size maps 10 and on fauling will report back to the user. "There is no information in the data base about the size of the parts." This gives the user some information about the what the data base contains. An answer like "I don" know what "big" means." would leave the user wondering whether size information was in the data base and obtainable if only the "right" word was used.

The system can interpret user statements that are not quertes. II the user says "A big supplier is a supplier that supplies more than 3 projects" the NLP can use the detintion in answering later queries. The definition is not made on a "string" basis e.g.. substicuting the words of one side of the Jetinition for the other. Instead. whenever the guery building digorithm encounters in instantiated concept that is a supplier with the condition "sizetr. big) it builds a query substltuting the condition from the definition that it can expand as a data hase querv Thus the ivetem can handle "big Iondon suppliers" and unswer "Which sunpliers are big" which it couldn it if il were doing stritt string subst1tution.

This facility un be used to bootstrap common detinitions in a commercial flights application. with data base scheme.

Flights (fl\#.currier.from.lo.departure.arrival.stops.cost the word "nonstop" is detined to the svstem in English as. "A non. stop flight is a flight that does not make any stops" and then saved atong with the rest of the svstem is detinitions. 
Coercions (section 2.) can be used solve problems that may require inferences in other systems. [Grosz 6] discusses the query "Is there a doctor within 200 miles of Philadelphia" in the context of a scheme in which doctors are on ships and ships have distances from cities. and asserts that a system which handles this query must be able to infer that if a doctor is on a ship, and the ship is with 200 miles of Philadelphia. then the doctor is within 200 miles of Philadelphia. Using coercions. the query would be understood as "is there a ship with a doctor on it that is within 200 miles of Philadelphia?", which solves the problem immediately.

Since the preference information is only used to choose among competing interpretations, broken preferences can still be understood and responded to. The preference for the supplier case is specified to "supplier but if the user says "How many parts does the sorter project supply?" the NLP will find the only interpretation and respond "projects do not supply parts. suppliers do."

Ambiguities inherent in attribute values are handled using the same methods which handles words with multiple definitions. For example. 1980 may be an organization number, a telephone extension. a number, or a year.

The NLP has a rudimentary (so far) expert system inference mechanism which can easily be used by the DBAP. One of the rules it uses is "If $x$ is a precondition of $y$ and $z$ knows $y$ is true then $z$ knows $x$ was and may still be true" One of the facts in the NLP knowledge base is that being married is a precondition of being divorced or widowed. If a user asks "Did Fred Smith used to be married?" in a data base with the relation Employees (name. marital-status) the system can answer correctly by using its inference mechanism. The exact method is as follows. The data base application receives the true-false question:

"Fred Smith was married and Fred Smith is no longer married"

Since the data base includes only current marital status information. the only way to answer the first part of the question is to infer it from some other information in the data base. The data base application sends the query to the NLP inference mechanism which would ordinarily attempt to answer it by matching it against its knowledge base or by finding a theorem which would gives it something else 10 match for. When called by the data base application. the inference mechanism simply uses its rules base to decide what it should match for, and then returns to the data base program. In this. example, the inference mechanism receives "Fred Smith was married" and using the precondition rule mentioned above, returns to the data base program. "Is Fred Smith Jivorced" or "Is Fred Smith widowed". which can be answered by the data base. The DBAP can call the inference mechanism recursively if necessary.

\section{Impiementation Status and Details}

The DBAP is fully impiemented und debugged. The NLP is implemented and stull growing. Both dre implemented in Franz LisD. I dialect of LISP. Language processing and query generation are performed in virtually real lime laverage 1.3 cpu seconds) on $\downarrow V a \times 11-780$.

The system is intended to be used with a Data Base Management ivitem. The interface between the DBAP and the DBMS is if siralghtiorward iranslator from relational algebra to the query language of the DBMS. I have written a Iransialor for Polaris [Gielan 4 l.
The system handles all the examples in this paper as well as wide range of others (Appendix A.). Several different data bases schemes have been connected to the system for demonstrations, including one "real data base" abstracted from the on-line listing of the Bell Laboratories Company Directory

\section{References}

1. Cohen. P., Perrault C, and Allen J., Beyond QuestonAnswering. Report No. 4644, Bolt Beranek and Newman Inc., May 1981.

2. Fillmore $\mathrm{C}$.. The Case for Case, in Universals in Linguistic Theory, Eds., Bach E, and Harms, R., Holt, Rineheart and Winston. New York, 1968.

3. Gawron M. G.. et. al.. Processing Englis/h with a Generalized Plinase Siructure Grammar. 20th Annual Meeting of the Association for Computational Linguistics. June 1982.

4. Gielan D., Polaris User Manual. New York Telephone Company, January 1981.

5. Ginsparg.J., Natural Language Processing in an Auromanic Programming Domain Memo 316. Stanford Artificial Intelligence Laboratory, Stanford University, 1978.

6. Grosz. B.. Transportable Nalural-Language Interfaces: Problems and Techiniques 20th Annuat Meeting of the Association for Computational Linguistics. June 1982.

7. Kaplan. S. J., Cooperarive Responses from a Portable Vaurat Language Data Base Query System. Ph.D. dissertation. Department of Computer and Information Sciences. University of Pennsylvania. Phila.. Pa., 1979.

8. Quillian, M. R., Semantic Memory, in Minsky. M.. Ed.. Semantic Information Processing. The M.I.T. Press. 1968.

9. Ullman, J., Principles of Database Systems. Computer Sci. ence Press. Potomac. Maryland, 1980.

\section{Appendix A: Sample Questions and Answers}

- does every department head in 1135 have an office in holmdel?

No. all heads that work for center number 1135 are not located in an office in ho

- who isn'?

alles.h $\mathrm{g}$ is the head nor located in an office in ho that works for center number 1135

"who has been with us for longer than fred smith"

There are no employees that have worked for you for more than the length of the time fred smith has worked for vou

- list the employees who used to be marrted and are not married now.

paul rochester, verion biggs and willie davis are the emplovees that were married and that are not married now. 
- production between february 1979 and april 1981

11352 - 768 - widget - march 1981

$11352 \cdot 888$ - widget - upril 1981

11352 - 133 - screw - jan 1980

11354 - 133 - widget - ian 1980

- who flies between london and paris

Iwa and pan am are the dirlines that fly from london into paris

- get me a flight to paris from london before $3 \mathrm{pm}$

a llight betore 1500 into paris from london

Il\# dirline departure arrival plane stops price

$\begin{array}{llllll}? & \text { pan am } 1+00 & 1800 & \text { dcl0 } & 0 & 180\end{array}$

- the latest light out of london

the latest tlight from london:

il a arline to departure arrival plane stops price

1 iwa paris 15001700 dcl0 $3280^{\circ}$

- who supplies more than two projects

bowles and blake are the suppliers that supply to more than 2 proiects

- who supplies more than the boss project

the suppliers that suppiv to the projects besides the boss project Ire:

Jecker. blake. howles and white

- who supplies more projects than Decker

howles and blake are the suppliers that supply to more projects than the number of the projects that are supplied to by decker

- list the suppliers who supply projects in cities they are not in

the suppliers that supply to the proiects loculed in the cities in which they are not locuted in are:

decker. blake. bowles and white

- how manv parts Joes whice iupply

There sre 9 parts supplied by white

- how many different parts does whue supply

There are 2 kinds of parts supplied by white

- what ase thev

hor and screw are the kinds of parts supplied by white

- who iupnlies the mosi kinds of parts

howles is the sunplier that supplies the most kınds of parts

- how many does it supnly

There are + kinds of parts supplied by the suppliers that supply the mosi kinds of parts
- how much does the mixer project spend on widgets from blake

+40 is how much was spent by the mixer proiect on widgets supplied by blake to it

- how much did the mixer projest spend on eact part

widget -649

box -3

- print the Jrinkers that frequent onlv bars that serve some beer that they like

george and john are the drinkers that irequent only bars that serve some beers liked by them 